The original article should be cited:

Representations of Ethnic Minorities in China's University Media, w/ ZZ Zhao,

Discourse: studies in the cultural politics of education 31(4), October

2010; pp. 1-18

\title{
Representations of ethnic minorities in China's university media
}

\author{
Zhenzhou Zhao $^{\mathrm{a} *}$ and Gerard A. Postiglione ${ }^{\mathrm{b}}$ \\ ${ }^{a}$ Hong Kong Institute of Education; ${ }^{b}$ The University of Hong Kong
}

\begin{abstract}
This paper examines the representation of ethnic minorities in China through a review of campus newspapers, a major print medium in which universities exercise power over the discourse of cultural recognition. Three universities attended by minority students were selected. A two dimensional mode (content and configuration) is established to analyze ethnic representations. A combination of content analysis and discourse analysis is used to categorize and analyze text and photographs relevant to ethnicity. The study concludes that (a) different discursive practices are employed to construct 'images' of ethnic groups as 'Others' or 'Us'; (b) representations of ethnic minorities and the Han generate three discursive dichotomies between minority and majority: minority groups are distinctive, potentially separatistic, and visible; and the Han people are normative, patriotic, and invisible, respectively; (c) the university media reflects an ideology of 'state multiculturalism' that constructs a reflexive representation of the relationship between majority and minority.
\end{abstract}

Keywords: university media; ethnic minority groups; representation; China; state multiculturalism; discourse

\section{Introduction}

Many multi-ethnic countries find themselves in a difficult dilemma between national unity and cultural diversity. China, with a large population from 56 ethnic groups, is one of them. The distinguishing feature of this socialist country is its directive and top-down approach in identification and categorization, social positioning, and representations of ethnic groups. This approach is referred to as duoyuan yiti geju (pluralistic unitary structure) ${ }^{1}$ by Fei Xiaotong (1992), or 'Chinese national multiculturalism' in Bulag's (2003) term. These two interpretations share a similarity in construing ethnic relationships in terms of 'group ranking', that is to say, the

\footnotetext{
* Centre for Governance and Citizenship, The Hong Kong Institute of Education, 10 Lo Ping Road, Tai Po, New Territories, Hong Kong. Email: zhaozz@ied.edu.hk
} 
subjugation of ethnic minority identities to an overarching and honorable identity of the Chinese nation. In this paper, we will argue how the discursive practices in campus print media construct an ideology of 'state multiculturalism' that reveals the assimilation impetus stemming from the Sinic civilization and Marxism projects and also reflects integrative representations of diverse cultural communities. A systematic analysis of linguistic devices in the university media, the main medium for the purpose of reporting major events and publishing teacher and student essays, illuminates how the lived experiences of different actors (university, staff and students) are woven into this ideological formation.

State multiculturalism is first grounded in its political construction of ethnicity. Although around 400 groups applied for registration as a nationality in the ethnic identification program ${ }^{2}$ initiated in the early 1950s, only 55 minority groups (Han as a majority is excluded) are recognized based on the criteria formed by Stalin in 1913 (i.e. common territory, language, economy, and psychological make-up manifesting in a common culture). A prominent example is ethnic Zhuang, a product of political engineering (Kaup, 2000). The state government also adopted direct actions in minority language maintenance and development. Since the 1950s, 32 writing systems have been created under the auspices of the state government to favour the minority groups who have no scripts for their spoken languages (Zhou, 2000). Although well intended, the use of these artificial scripts remains limited.

Social positioning in this paper refers to affirmative actions toward ethnic minority members in political representation, employment, and education. Since the mid-1980s, the central government has implemented preferential policies in family planning, education, employment, business development and political representation in order to improve ethnic minorities' access to economic development opportunities and social equity (Sautman, 1999). These policies aim to improve ethnic minorities' social-economic and educational development (Wang \& Zhou, 2003). In higher education, ethnic minorities are awarded extra points on their college and university entrance examination, provided with increased placement opportunities in the country's 13 nationality universities and colleges, and, in certain cases, are permitted to take the entrance examination in their native written language (Sautman, 1999).

In terms of representation, China's pattern of multiculturalism is an exercise of power for political control, which is achieved by a set of 'dominant and legitimate language' (Bourdieu, 1991, p. 5) in the state-controlled media. They embody a distinct form of rhetorical devices, genres, and manners and formulations, for example, the people (renmin), masses (qunzhong), and the comrade (tongzhi). Ironically, the term 'comrade' has come to be used to refer to gay people in unofficial publications in the post Mao era. Dominant and legitimate language is structurally guaranteed through media censorship in a system under the authority of the Chinese Communist Party (CCP). In other words, media is the official version of the dominant ideology. Research has found that the mass media permit space to represent and give voice to ethnic identities, which have experienced a higher profile through the 1980s and 1990s (Mackerras, 1995). Yet, their images are often constructed as primitive, sensual, and exotic subjects (Gladney, 1994a).

Socialist China is not alone. A large number of studies have examined how ethnic groups are represented in newspapers, television, radio and other media. More often than not, ethnic minorities are represented with biased images favouring the standpoint of the majority ethnic group, and their participation in the mass media is very limited (Gardikiotis, Martin, \& Hewstone, 2004; Pietikäinen, 2003). Poindexter, 
Smith, and Heider (2003) found that Latinos, Asian Americans and Native Americans are invisible in the role of news anchors, and TV reporters; and as subjects in the news, African Americans are generally segregated in story assignments; and, ethnic minorities are seldom represented as news sources. Apart from their less frequent representations in the media, the images of minorities are shaped by stereotyped descriptions. For example, Henley et al. (2002), in a content analysis of over two centuries of popular stereotypical depictions of Louisiana Cajuns, found that negative portrayals are given to Cajuns by outsiders and these in turn are changed by selfrepresentation of Cajuns themselves. Campbell (1995) examined television newscasts in America, and stated that the media lead the public to consider minority cultures as valueless and marginal. The research mentioned above indicates that the seemingly common sense and taken-for-granted media of the majority group marginalize ethnic minorities and frame stereotypical representation. The news media are generally involved in shaping and reflecting 'the dominant notion of what is significant' and 'the ongoing process of constructing a dominant ideology', thus comprising a full circle between discursive practice and reality (Erjavec, 2001, p. 702). The readers or audience often regard the dominant ideology expressed in the news as normal and something to be taken-for-granted, as ethnic minority groups may often be constructed into stereotypical and categorized representations (Gardikiotis et al., 2004).

However, very few studies have paid attention to representation of ethnic minorities in media of the educational arena, especially in China. The campus media exposes the social and cultural construction of ethnic representation grounded in the state ideology, and also provides a niche for critical intellectuals working at universities and passionate students to negotiate with the state ideology. In this sense, the campus media encounters a contested terrain of absorbing different voices and justifying the dominant ideology. An analysis of ethnic representations in the campus media contributes to an understanding of how Chinese universities tackle the issue of cultural diversity while granting preferential admission to ethnic minorities in a context of discourse guided by state multiculturalism.

\section{Campus newspapers}

The campus newspaper (hereafter CNP, xiaobao), is students' main source of information on university regulations, administration, and campus news, and it is freely accessible to the public both in hardcopy or electronic version. They are viewed by students and staff as exerting a strong influence on campus life. The CNPs deliver the latest news and have the largest circulation of any printed news medium on campus. Their main role is to report important events happening on campus and deliver public opinions among the campus community, including leaders, teachers, students and others.

Campus newspapers at three types of higher education institutions attended by minority students were selected: Inner Mongolia Normal University (IMNU), Beijing Normal University (BNU) and South China's University for Nationalities (SCUN). ${ }^{3}$ These universities represent respectively (1) a university under the governance of an ethnic autonomous region; (2) a university under the State Ministry of Education with a heavy emphasis on teacher education; and (3) a university under the Ethnic Affairs Commission, specifically designated for different nationalities, but also attended in 
significant numbers by Han students. These three universities were selected for the following reasons: first, all are comprehensive universities, despite the former two universities having a strong tradition of teacher education; second, all belong to the three types of higher education institutions that minority students attend in China. For the IMNU, the student body is mainly composed of Mongols and Han Chinese; BNU is predominately a Han institution that recruits students nationally; and, SCUN is a university that was established specifically for ethnic minority groups; and third, all are located in a different capital city. IMNU is located in the capital of Inner Mongolia Autonomous Region, BNU in the national capital, and SCUN in the provincial capital of Hubei.

The three CNPs are published regularly (IMNU CNP is issued once a month, and CNP of BNU and SCUN three times per month). The only time that CNPs stop publication is during winter and summer holidays (late January and February, and late July and August). The period covered is between 1995 and 2004 for IMNU and between 2000 and 2004 for SCUN (see Table 1). ${ }^{4}$ CNP publishes by a special office called 'the CNP Editorial Office' (Xiaobao bianjibu), made up of full and part-time student journalists. Due to their authoritative role and easy access, CNPs exert a huge influence on teachers and students' notions of ethnic minorities on campus.

\section{Multiculturalism and Otherness}

A cornerstone of multiculturalism is to recognize cultural differences between ethnic groups but put the differences within the overarching similarity between all human actors. This notion focuses on 'the similarities and uniqueness of each culture' on one hand, and 'an attempt to integrate cultures through contact and working towards reducing prejudice through a paradigm of improving human relations' on the other (Rezai-Rashti \& McCarthy, 2008, pp. 529-530). The idea of multiculturalism is also manifested in the guiding ideology of duoyuan yiti geju (pluralistic unitary structure) as set out by Fei Xiao-tong to explain the formation of the Chinese (Zhonghua) nationality.

The concept of a single Zhonghua nationality for all Chinese citizens that embraced all other ethnic identities - Hans, Uyghurs, Yaos and everyone else ... Zhonghua nationality has a 'pluralistic unitary structure': the distinct identities of the various nationalities, though still recognized, are secondary to their identities as Zhonghua; the whole course of Chinese history has led to the fusion of what had been distinct ethnic groups into one. (Translated and cited in Jenner, 2001, p. 73).

This ideology cultivates a dual image of ethnic minorities; that is, represented as 'Others' to denote pluralism and as 'us' to denote unity. Yet it is argued that China's pattern of multiculturalism exposes minorities to an 'internal Other' (Bulag, 2003). Gladney (1994b) describes how ethnic minorities are constructed as 'Others' in China's state-sponsored media. Similarly, Schein (2000, p. 283) argues that minorities are exposed to 'the production of Otherness' on account of being modern.

The dichotomies of self-representation vis-à-vis the Other is a colonial construction by power; and an unequal power relationship 'determines which characteristics are the norm and are superior to Others' (Kubota, 2001, p. 28). It is through discourse that the exercise of colonial power constructs the subjects embodying 'an articulation of forms of difference’ (Bhabha, 2004, p. 96). Hereby, 
discourse analysis is a powerful tool to research 'the way social power abuse, dominance, and inequity are enacted, reproduced, and resisted by text and talk in the social and political context' (Van Dijk, 2001, p. 352). A rich and varied collection of studies using the lens of discourse examined print media to reveal ethnic, gender and other forms of inequality and injustice (e.g., Gotsbachner, 2001; Johnson \& Avery, 1999; Wodak \& Reisigl, 2001). For example, Teo (2000) found that the discourse of two major newspapers in Sydney portrays minorities as criminal and voiceless, with Vietnamese represented with the stereotypes of being dangerous 'Others'. Flowerdew, Li, and Tran (2002) reviewed Hong Kong print media and identified four overlapping strategies: (a) negative other presentation; (b) scare tactics; (c) blaming the victim; and (d) de-legitimation. All four strategies have been used in the South China Morning Post to discriminate against Chinese mainlanders. Pietikäinen (2003) applied critical discourse analysis to examine how Finnish newspapers represent the indigenous Sami people, and revealed five different features between the Sami and the Finnish: invisible vs. visible, voiceless vs. voiced, affected participant vs. acting participant, nature-dominated vs. legislative establishment and homogeneous group vs. homogeneous system. As a result, the Sami suffer from stereotypical representation and maintain a marginalized position in the mainstream media.

\section{Mode of ethnic representation}

This paper extends Kubota's (2001) framework about the construction of the dichotomous images of the Self and the Other. We establish a two dimensional mode to analyze the discursive representation of ethnic minorities and the majority Han in the CNP. The first dimension, content dimension, categorizes the images into three approaches: (1) portraying ethnic minorities as 'Others'; (2) portraying ethnic minorities as 'Us'; (3) portraying the majority (Han). The second dimension focuses on how the media contextualize ethnicity (concepts selected for coding include the term 'ethnic group' and the names of 56 ethnic groups); and symbolize ethnic groups (for example, Morinhuur, a traditional symbolic music instrument used by the Mongols). It is called the configuration dimension. This mode of ethnic representation (content and configuration) is applied with a mix of quantitative content analysis and qualitative discourse analysis (to examine specific discursive strategies).

The combination of content analysis and discourse analysis is used to categorize and analyze text and photographs relevant to ethnicity (Titscher, Meyer, Wodak, \& Vetter, 2000). Regarding the text, content analysis is used to identify and categorize pieces of news relevant to ethnicity. ${ }^{5}$ As shown in Table 2, the SCUN CNP has a pronounced tendency to portray ethnic minorities as different (88.4 per cent); while the BNU CNP, in contrast, has an equally pronounced tendency to project the image of ethnic minorities as 'Us' (70.9 per cent). The IMNU falls between these two extremes but with a slight emphasis to construct ethnic minorities as 'Others' (63.6 per cent). Content coding of photos is carried out in three stages: first, all the photos pertaining to ethnic minorities are categorized into two groups: one depicting people and the other includes scenes, architecture and so on. We found that persons are more likely to be represented than objects (e.g., scene, art products). In the SCUN, human photos number 59 with a frequency of 78.7 per cent of the total; they are also the most frequent category in the BNU CNP, reaching 93.3 per cent; and human photos occupy 92.3 per cent of the total number of photos in the IMNU CNP. The second stage of 
categorization focuses on whether the people are portrayed as wearing their ethnic costumes and ornaments or not. Finally, the third stage examines the gender and actions of the human figures. Across the three newspapers, the female figures largely outnumber male ones. We will present detailed information about the people's ethnic appearance and actions in the following themes.

\section{Portraying ethnic minorities as 'Others'}

The portrayal of ethnic minorities as 'Others' takes four different forms. The first is a focus on unique ethnic characteristics, including customs, songs, dance, and tourist sites. The second highlights reliance on external aid, presentation of customs, and positive cases of political involvement. A third form describes practices of ethnic minority culture, and finally, a fourth reports minority members' narratives about ethnic identities. We provide an analysis of how these forms appear in each CNP in Table 3. IMNU made a greater effort to cater for minorities' cultural practices (Form 3: 71.8 per cent), especial Mongolians, because of its regional context. These consist of implementing bilingual education (Mongolian and Chinese languages), holding activities characteristic of Mongols, or academic business on Mongolian studies. The BNU CNP also tends to place emphasis upon the distinct ethnic features and practices of minority groups. The SCUN gives prominent attention to depicting ethnic minorities' different features through form 1 (57.6 per cent).

The first strategy constructs an image of ethnic minorities as 'Others' on the basis of unique ethnic features, such as history, customs, religion, and residence in areas popular with tourists. In the SCUN CNP, a regular column called 'ethnic customs' (minzu fengqing) was established to introduce minorities' cultural practices, for example 'Customs and Habits of the Ethnic Buyi Group' (10 April, 2004, SCUN). The BNU CNP features essays about tours of ethnic areas, as in 'A Trip to A'li' (20 October, 2004, BNU) which describes beautiful and natural scenes in A'li, an ethnic minority area.

The second form gives a depiction of ethnic minorities as in need of cultural care, external aid, and political representation. When BNU CNP reported a ceremony of a computer donation program, an ethnic minority teacher delivered the opening address: 'I come from a relatively economically-backward area, and so I especially understand the kids' hopes for computers in poor areas' (25 February, 2000, BNU). In a speech at the 50th anniversary celebration of the university by the SCUN president, ethnic minorities are portrayed as having been culturally backward for thousands of years, ... and SCUN as having contributed to changing this history: 'During the fifty years' struggle, (SCUN) rewrote minorities' history of a thousand years of cultural backwardness' (29 November, 2001, SCUN). The following extract describes that the university establishes a Muslim canteen on campus out of concern for minority group' ethnic beliefs and in turn minority students expressed their deep gratitude. The use of 'they' in the quote exposes the position of minorities as 'Others'. This discursive practice conveys a paternalism among the mainstream society toward minorities, as in this selection from the CNP of SCUN in which the university leaders as an agent of the authorities are portrayed as caring and tolerant:

A Small Rice Bowl is Full of the Leader's Concern: The Catering Commission held a meeting about the Muslim canteen. At the meeting, the student representatives first presented their points of view, that the university's setting up of a Muslim canteen for Hui students shows 
respect for their ethnic beliefs and the Hui students expressed their appreciation to the university. (11 May, 2003, SCUN)

In addition, many campus committees report the percentage of ethnic minority (and women) representatives in the news on political activities. These discursive practices reflect a stereotypical image of ethnic minorities as economically and culturally backward. In contrast, the majority Han group renders aid by offering resources and concerns for their customs and political involvement. As a result, they are very grateful to 'Us'.

The third form includes newspaper articles about minorities' cultural practices, including the development of education that is especially for minorities, as well as academic works about ethnic history and culture, ethnic language usages, ethnic art, sport games, etc. For instance, SCUN reported that Hubei province held a traditional ethnic minority sports event (17 October, 2002), and IMNU held a handwriting and speech competition in Mongol and Chinese languages (28 October, 1998). Ethnic songs and dance (minzu gewu) also play a central role in this form of representation, especially in BNU and SCUN, though less so at IMNU (Table 4). A close examination of the ethnic minority characters in the photo also shows 'singing and dancing' are highly represented, particularly BNU and the SCUN CNPs (see Table 7). The 'Others' forms reflect a stereotypical image of ethnic minorities in China: 'having a gift of singing and dancing' (nengge shanwu).

In terms of the photographs, ethnic costumes and decoration are taken as symbols of ethnic minorities, and this manifests itself in the fact that more than 90 per cent of the ethnic minority pictured show them in their ethnic dresses (Table 6). While wearing ethnic costumes is an essential part of cultural practice, minorities seldom wear their dress on campus. However, the CNP discourse conveys the opposite impression. For example, one story depicts a Dai girl who could not get accustomed to the Han costumes and asked her family to send her ethnic Dai attire from her hometown far away. This report portrayed the Dai female student as attracting attention when she wore her traditional ethnic dress on campus (29 September, 2000, SCUN). The report hesitates to mention that ethnic costumes are seldom worn on campus and does not speculate as to why.

Finally, the CNPs also give minority members limited room to voice their subjective feelings toward their ethnic membership. For example,

Travel to Seek My Roots: Growing up in the Han area, I do not consider myself different from others. However, I keep a clear mind about being a member of the Mongol group ... (22 November, 2003, SCUN)

The function of this representation is to illuminate the ability of ethnic minorities to assert their ethnic identity in a multi-ethnic community. Yet, this form of strategic representation appears in a minority of cases (less than 5 per cent). In all three university media under analysis, the voices of ethnic minorities are silent or are selected to harmonize with the dominant ideology (Teo, 2000).

These four forms provide a cultural portrait of ethnic minorities as distinct from the majority Han; as the object of paternalistic treatment; as liberal agents practising their culture; and as independent individuals asserting their ethnic identities. 
Other discursive mechanisms of representation are used to portray ethnic minorities as 'Us'. Some articles employ the collective ethnic concept (ge minzu or minzu) and emphasize inclusion of all ethnic groups; Others use the idea of Chinese nation (Zhonghua minzu); and yet, others use the concept of ethnic unity (minzu tuanjie). The frequency of these different forms is shown in Table 5.

Representing all ethnic groups together (ge minzu) is a widely used strategy in the CNP when reporting an event, for example, as in the headline 'All Ethnic Group Students Learn from Xu Zhi-wei' (10 March, SCUN). 'Learning from a hero' is constructed to propagate the notion that ethnic minorities are unified, together with majority Han, in support of campus activities. Similarly, the following extract depicts a movie, Gada Meilin, in which this Mongol hero fought against the Han Chinese' farming on the Mongolian prairie grasslands.

\footnotetext{
Gada Meilin is a story of a Mongol hero living seventy years ago, who led ethnic group members in revolt in order to protect the grassland and the ordinary people. (31 October, 2003, BNU)
}

The Mongol hero is represented as having led all ethnic groups in a struggle to protect the prairie grasslands, rather than as a case of Mongol versus Han. Thus, the Han as adversary is missing in this story, and instead 'ethnic groups members' (ge minzu) expressed in this report is cast as including the Han. The theme of ethnic unity hides the reality of ethnic conflict, despite the well-known history of the Mongol-Han conflicts of the $12^{\text {th }}$ century.

Such a strategy also entails the use of general concepts of ethnic group, such as ethnic tradition (minzu chuantong) and ethnic dignity (minzu zunyan). In this way, the differences among ethnic groups are disguised, ignored or de-emphasized, with all combined as 'Us'.

The Chinese nation is frequently used in the BNU CNP to represent the final goal of collective unity of all ethnic groups in China - as in the great Chinese nationality. This discursive strategy blurs the ethnic boundary between minority and Han with the former constructed as 'Us'. A speech on the $50^{\text {th }}$ anniversary of IMNU asserts:

\footnotetext{
In the coming fifty years, our goal is to accomplish great revival of the Chinese nation, and make new and bigger contributions to economic and social progress for the bordering ethnic minority area, and the central and west region. (24 October, 2002, IMNU)
}

The idea of ethnic unity (minzu tuanjie) or reporting the news about an ethnic unity prize (minzu tuanjie jiang) is also frequently employed to construct 'Us' images of ethnic minorities. That minorities have the potential to create ethnic separatism is thus notable and mentioned in a selection from the Life of Comrade Bai Shou-yi: 'As an ethnic minority member, he has contributed so much especially to ethnic unity’ (21 April, 2000, BNU).

\section{The Han's images}


In the PRC, the Han ethnic group represents the overwhelming majority of the Chinese population, but this group is not represented as culturally distinct. Instead, they are portrayed 'as a group that resulted from an intermixing and fusion of many different peoples over a long historical period of several thousand years' (Postiglione, 2008, p. 146). In ancient China, classification of people depended traditionally on geographic location and cultural characteristics, rather than on minzu (ethnic group). Generally speaking, there were two categories: the central (zhongtu) and the peripheral people (siyi). Using ethnic groups as the criteria for classifying people did not start until modern China. The concept of 'minzu' was borrowed from the Japanese, and according to Liang Qi-chao, it was conceptualized in 1903 to pursue a political rationale for Nation-State Building (Dikotter, 1992). Sun Yat-sen, who led China's republican revolution in 1912, made an initial attempt to categorize the Chinese based on five ethnic groups (Han, Manchu, Mongol, Muslim, and Tibetan). After the foundation of the PRC, the Chinese government launched an ethnic identification program throughout the country from 1953. Rather than being based on physical and anthropological race criteria common in the West, Chinese ethnic minority identification relied on Joseph Stalin's criteria (Fei, 1992). Consequently, 56 nationalities were recognized and all these except the Han were called ethnic minorities. Based on Marxist historical trajectory from a lower to higher level, the Han Chinese are often represented as being closer to 'modern' ends than their ethnic minority brothers (Gladney, 1994b). The similarity of these three CNPs is that they present very few images of the Han. Generally speaking, the word of 'Han' is used to introduce someone's ethnic identity as background information (see the following extract), or describe history and the Chinese language (also called 'hanyu', the language of Han); for example,

Ping Zi-liang, Han, born on Oct. 31st, 1945. (31 October, 2001, IMNU)

\section{State multiculturalism: three discursive dichotomies}

Representations of ethnic minorities and the Han generate three discursive dichotomies between minority and majority: minority groups are distinctive, potentially separatistic, and visible; and the Han people are normative, patriotic, and invisible, respectively.

\section{Distinctive versus normative}

Members of minority groups are rendered distinct as 'Others' while defining the majority Han as normative. The frequency of four discursive forms in portrayal of ethnic minorities as 'Others' shows that ethnic minorities are more prone to be represented as different from the Han and practising their cultural ways. The linguistic strategies include a regular column to introduce ethnic minorities' customs and folklore, the image of singing and dancing depicted as an essential theme when portraying minorities, and ethnic costumes as an essential strategy to feature the characters' group identities (as fully demonstrated in the photo analysis). Particularly, the stereotypical representations are frequently seen for the BNU where the Han is by 
far the dominant student group. Such representations of minority group images strengthen the distinctiveness and assume the majority Han as the norm.

The photo analysis also shows that there is a high proportion of female portraits, with very few men in these photos; there are either more women or couples. In the pictures of singing and dancing settings, female performers largely outnumber the males. Clyne's (1995) argument about feminine forms for ethnic labels in text may shed light on this gendered representation of minorities, namely, that there are particularly more female performers in 'singing and dancing' and minority women as popular themes in figure portraits, a discriminatory discourse taking photographic form. Similarly, Schein (2000, p. 274) argues, 'Minority women were consigned to the position of conservators of tradition through dress'. However, this gendered representation does not relate to any erotic sense of portraying ethnic minorities as women, as was argued by Gladney (1994b) and Schein (2000).

\section{Separatistic versus patriotic}

The linguistic mechanisms of portraying minorities as 'Us' contribute to, in Benedict Anderson's (1991) term, an ‘imagined' construction of ethnic minority groups, together with the Han majority, constituting the Chinese, and furthermore, supporting ethnic unity. The heterogeneity within minority groups (e.g., a special column to present diverse customs among ethnic minorities), makes a striking contrast with the description of the Han majority as a homogenous and united body, despite varieties of Chinese dialects and richness of local cultures. Furthermore, the over-emphasis of ethnic unity implicitly puts ethnic minorities in a danger of having potential intention to be separatists. This is fully demonstrated in the story of 'Life of Comrade Bai Shou-yi'. As mentioned above, singing and dancing are used more when depicting minorities' practising their culture. This is because performances of ethnic song and dance at campus events as the best way of showing respect for minority culture according to interviews with university administrators, since entertainment relates little to state security (Zhao \& Postiglione, 2008). Mackerras (1995) notes that his review of China's ethnic policies suggests that Chinese authorities do not inhibit ethnic minorities' cultural representation, but rather, they produce selective representations meant to support harmony and national integration. Also, Hansen (1999) points out that the priority of school education for minority groups is patriotism and cultural homogenization for the purpose of China's national integration.

\section{Visible versus invisible}

It is difficult to locate Han group images in the CNP's discursive practice. The CNP constructs an 'imagined' dichotomy between ethnic minorities and the Han through highlighting the identity of the former and hiding the latter. This strategy of minority visibility contrasting with Han invisibility in the Chinese context makes a difference from the two basic types of strategies used to justify inequity, that is, positive selfrepresentation of one's own group and negative representation of 'Others' according to Critical Discourse Analysis (Van Dijk, 1993). Dikötter (1992, p. 9) states: 'to mark, natualize and rank real or imagined differences between population groups' is widespread in China in the $20^{\text {th }}$ century, in order to construct 'symbolic boundaries 
between racially constituted categories'. For instance, when the news reports an opening ceremony of a computer donation program, the speech by an ethnic minority teacher about the need for computers in ethnic areas is emphasized. Yet, the image of the majority Han group, the donor, is ignored. Compared with ethnic minorities, the Han group lacks its own ethnic features and images. As Gladney (2004, p. 47) notes, the invisibility of the majority Han is 'at the expense of the visibility of the displayed minority'. The songs/dances of ethnic minorities are commonly called 'ethnic songs/dance' (minzu gequ/wudao), or a specific ethnic group’s song/dance, for example, Mongolian dance (menggu wu). Also, ethnic minorities' costumes are represented in the photos. The CNP does not show special songs and dances of the Han, nor their customs. If any are shown, they are in the name of Chinese or Chinese nationality. This hidden Han group indicates that the Han is an 'imagined', normal and 'unmarked' category (Gladney, 1994b), and identification of the Han entity needs to depend on the representation of ethnic minorities as 'Others'. Taken together, these three discursive dichotomies show how the government sponsored ideology solves the problem of maintaining minority groups' cultural identity and integration into the national mainstream. We would now like to develop a little further the concept of state multiculturalism given at the start of the article.

Since the notion of 'multiculturalism' was introduced in Canada in the 1970s, different approaches have been developed based on diverse contexts around the world. Based on societies outside the common boundaries of Anglophone nations (such as Singapore, Malaysia, and Latin America), the term 'state multiculturalism' increasingly gains attention as a way of the management of diversity forged by the state apparatus in the public domains of politics, economy, education and law (Horton, 2006; Raihanah, 2009). Rather than committed to removing inequality and empowering vulnerable minorities, state multiculturalism 'imposes limits upon the recognition and interrogation of cultural difference' (Goh, Gabrielpillai, Holden, \& Khoo, 2009, p. 3). The Chinese pattern of state multiculturalism, as argued in this paper, is formed in a non-postcolonial (at least strictly speaking) and indigenous multiethnic context.

State multiculturalism paints a picture that China protects and fosters traditional cultures of diverse ethnic groups, as stated in The White Paper of Regional Autonomy for Ethnic Minorities in China (2005). This is clearly demonstrated in the discourse of the CNPs. For example, the authorities and universities help minority groups, are concerned about their customs, and foster their political involvement. Spontaneous minority narratives reinforce an image of ethnic identity maintenance with a tolerant and pluralistic university community. State multiculturalism is grounded in two rationales. First, the disparity of 'civilization' between majority and minority, which can be traced back to the ancient Chinese philosophy and Marxism, grants minority members' tolerance-oriented recognition, instead of respect and full participation. This accounts for the fact that cultures of ethnic groups are devalued and are explained as an obstruction to their development and modernization, which has been discussed in various studies on Chinese minorities (e.g., Hansen, 1999). Second, diversity is construed within the frame of 'Chinese nation' and serves to defend the integrity of the state. This contributes to an asymmetric fabric of representations between majority and minority. The dominant discursive practice highlights the distinct cultural features of ethnic minorities while hiding those of the Han Chinese majority. The case of Tibetan students in primary and secondary education by Postiglione, Zhu, and Ben (2004) also shows that the schools do not 
overtly exclude their cultural representations, rather they select and interpret the practices based on the ideology of state integration. Under the ideology of state multiculturalism, ethnic differences are shaped according to the majority's imagination, and ethnic minorities are confined to the officially sanctioned images. Inevitably, this produces stereotypical representation of ethnic cultures, which yet functions to foster an appealing image of a unified and diversity embracing country.

The CNP of each university demonstrates a similarity in the forms of cultural representation for ethnic minorities, owing to their subjugation by the dominant ideology, state multiculturalism. Taken together, the CNP yields an image of ethnic minorities grounded in this ideology: (a) minority groups have features distinct from the majority Han, perform their cultural practices, especially singing and dancing, and their members remain conscious of their ethnic identity; (b) they obtain paternalistic aid from the Han Chinese and are harmoniously involved in political activities, while their ethnic customs are fully respected; (c) together, minorities strengthen ethnic unity within the configuration of the Chinese nationality. China's case demonstrates that state multiculturalism constructs a reflexive representation of the relationship between majority and minority. The majority group is substantial and an authentic norm for the community. But ethnic minorities are a mirror image that the majority encounters, and embody the imagined 'Otherness'. Although the two images are deemed to share an essential identity, the minorities’ images are transformed, distorted, and imaginative casting.

\section{Concluding remarks}

The CNP discourse portrays dual minority images under the ideology of state multiculturalism: on the one hand, ethnic minorities are constructed as 'Others'; on the other hand, they are represented in the dominant ideology of the state as a part of 'Us'. The three CNPs differ in the degree to which they construct one or other of these two images. IMNU tends to portray ethnic minorities as 'Others' to a greater degree than as 'Us'. In BNU, the CNP portrayal of ethnic minorities as 'Us' predominates; and in SCUN, the CNP image of ethnic minorities as 'Others' is also greatly overrepresented. Taken together, representation of the Han at IMNU and SCUN is minor. The differences between the three universities derived from the above analysis can be interpreted in terms of three primary factors: university status, location, and student composition. As a university governed by the State Ministry of Education, BNU gives less cultural recognition to ethnic minorities and is Beijing based with a higher proportion of Han students than the other two universities. IMNU, under the governance of the Inner Mongolia Autonomous Region, projects greater and more accurate cultural recognition of Mongols than BNU. SCUN is administered by Ethnic Affairs Commission and a multi-ethnic institution with more minorities than Han students, though it is located in the Han Chinese city of Wuhan. Furthermore, IMNU is the only university of the three that has both a Chinese and Mongolian language streams. In terms of the student composition, ethnic minority students occupy 46 per cent $(15,623), 10.8$ per cent $(8,400)$, and 54 per cent $(16,500)$ in the undergraduate student body of IMNU, BNU, and SCUN, respectively. ${ }^{6}$ IMNU is mainly composed of Mongols and Han, but the other two universities have far more ethnic minority students recruited from across the country. 
Although the CNP may be controlled by the university authorities, it is not simply a propaganda tool (see Bennett, 2005). Our analysis in this paper suggests that representations of ethnic minorities, underpinning an ideology of state multiculturalism, are achieved by 'the collective unconscious' of the majority group by obscuring the real condition of society both to itself and to others (Mannheim, 1991). As noted above, CNP journalists include a great number of students in their news stories. Interviews with over 122 students and teachers (including Han and minorities) echo the findings displayed above. For example, asked what kind of information on minorities she could learn from campus media (e.g., the campus newspaper), a postgraduate Mongol student in BNU, responded:

Negative and one-sided. I seldom find that, for example, a person who has made a great contribution is recognized as coming from the Inner Mongolia Autonomous Region. The information implies that minorities are poor; or celebrate some distinctive festivals. This means that ethnic areas are backward, and still celebrate such festivals now! (Interview conducted on 7 November, 2004)

Accordingly, the CNP displays a discourse about ethnic minorities, one which has a great influence upon the campus climate through its recognition by the members of the university community. Further improvement might be obtained by recruiting more minority students in the group of journalists (they are usually excluded on an account of the Chinese language proficiency) and assigning more space for them to represent their own voices, values, and lives.

\section{Acknowledgements}

We are grateful to Dr Chen Bateer for his assistance in the fieldwork, and Professor Fazal Rizvi and the anonymous reviewers for their helpful and constructive comments.

\section{Notes}

1. Some other scholars have translated 'duoyuan yiti geju' as 'Plurality and Unity in the Configuration of the Chinese Nationality’. See for example Gladney, D.C. (2000, March).

2. Shortly after the foundation of the PRC in 1949, a large-scale program of team fieldwork including linguists, ethnographers and historians embarked on a journey to identify nationalities across China.

3. The three campus newspapers are respectively called the Inner Mongolia Normal University Campus Chronicle (Neimenggu shida bao), the Beijing Normal University Times (Beijing shifan daxue xiaobao), and the South China's University for Nationalities Post (Zhongnan minzu daxue xuebao). IMNU has two types of CNPs: the Mongolian language version and the Chinese version. This study uses the Chinese version since it has a larger coverage and more influence on campus life. The Chinese university newspaper was named IMNU Weekly (Shida zhoubao) before July, 2001.

4. The reasons why six and seven copies of the BNU and the IMNU CNP are missing respectively are that all CNPs are stored only in their editorial offices and some issues are missing there. The number of issues, items of news relevant to ethnicity, and photos in each CNP are shown in Table 1.

5. It should be noted that the unit of analysis in this study is every item of news information we retrieved, and therefore, it will be counted only once despite the same ethnic concept's possible repetition in one piece of news.

6. These are the figures for when the research was conducted in 2004. 
Table 1. Basic CNP information

\begin{tabular}{|l|l|l|l|l|l|l|}
\hline & Coverage & Frequency & $\begin{array}{l}\text { No. of } \\
\text { Issues }\end{array}$ & Size & $\begin{array}{l}\text { No. of items } \\
\text { of news } \\
\text { relevant to } \\
\text { ethnicity }\end{array}$ & $\begin{array}{l}\text { No. of photos } \\
\text { relevant to } \\
\text { ethnicity }\end{array}$ \\
\hline IMNU & $\begin{array}{l}\text { Jan. 1995 - } \\
\text { Aug. 2004 }\end{array}$ & Monthly & 88 & $\begin{array}{l}\text { A3, 4 pages } \\
\text { (Jan. 1995 - } \\
\text { Jul. 2001); } \\
\text { A2, 4 pages } \\
\text { (Jul. 2001- } \\
\text { Aug. 2004) }\end{array}$ & 379 & 13 \\
\hline BNU & $\begin{array}{l}\text { Jan. 2000 - } \\
\text { Nov. 2004 }\end{array}$ & $\begin{array}{l}\text { Once per 10 } \\
\text { days }\end{array}$ & 119 & A2, 4 pages & 206 & 15 \\
\hline SCUN & $\begin{array}{l}\text { Jan. 2000 - } \\
\text { Nov. 2004 }\end{array}$ & $\begin{array}{l}\text { Once per 10 } \\
\text { days }\end{array}$ & 108 & A2, 4 pages & 328 & 75 \\
\hline
\end{tabular}

Table 2. Portrayal of ethnic minorities as 'Others' and 'Us' and portrayal of the Han

\begin{tabular}{|l|l|l|l|l|}
\hline & Others & Us & Han & Total \\
\hline IMNU & $241(63.6 \%)$ & $121(31.9 \%)$ & $17(4.5 \%)$ & $379(100.0 \%)$ \\
\hline BNU & $46(22.3 \%)$ & $146(70.9 \%)$ & $14(6.8 \%)$ & $206(100.0 \%)$ \\
\hline SCUN & $290(88.4 \%)$ & $33(10.1 \%)$ & $5(1.5 \%)$ & $328(100.0 \%)$ \\
\hline
\end{tabular}

Table 3. Portrayal of ethnic minorities as 'Others'

\begin{tabular}{|l|l|l|l|l|l|}
\hline & $\begin{array}{l}\text { Form 1 } \\
\text { Emphasize } \\
\text { unique ethnic } \\
\text { features }\end{array}$ & $\begin{array}{l}\text { Form 2 } \\
\text { Render } \\
\text { paternalistic } \\
\text { care }\end{array}$ & $\begin{array}{l}\text { Form 3 } \\
\text { Display } \\
\text { cultural } \\
\text { practices }\end{array}$ & $\begin{array}{l}\text { Form 4 } \\
\text { Represent } \\
\text { students' feeling } \\
\text { of ethnic identity }\end{array}$ & Total \\
\hline IMNU & $50(20.7 \%)$ & $13(5.4 \%)$ & $173(71.8 \%)$ & $5(2.1 \%)$ & $241(100.0 \%)$ \\
\hline BNU & $18(39.1 \%)$ & $8(17.4 \%)$ & $19(41.3 \%)$ & $1(2.2 \%)$ & $46(100.0 \%)$ \\
\hline SCUN & $167(57.6 \%)$ & $17(5.9 \%)$ & $96(33.1 \%)$ & $10(3.4 \%)$ & $290(100.0 \%)$ \\
\hline
\end{tabular}

Table 4. Portrayal of minority cultural practices of singing and dancing

\begin{tabular}{|l|l|l|}
\hline & Singing and dancing & Total \\
\hline IMNU & $15(8.7 \%)$ & $173(100.0 \%)$ \\
\hline BNU & $13(68.4 \%)$ & $19(100.0 \%)$ \\
\hline SCUN & $35(36.5 \%)$ & $96(100.0 \%)$ \\
\hline
\end{tabular}


Table 5. Portrayal of ethnic minorities as 'us'

\begin{tabular}{|l|l|l|l|l|}
\hline & $\begin{array}{l}\text { Collective ethnic concept } \\
\text { (ge minzu or minzu })\end{array}$ & $\begin{array}{l}\text { Chinese nation } \\
\text { (zhonghua minzu })\end{array}$ & $\begin{array}{l}\text { Ethnic unity } \\
\text { (minzu tuanjie })\end{array}$ & Total \\
\hline IMNU & $61(50.4 \%)$ & $44(36.4 \%)$ & $16(13.2 \%)$ & $121(100.0 \%)$ \\
\hline BNU & $78(53.4 \%)$ & $65(44.5 \%)$ & $3(2.1 \%)$ & $146(100.0 \%)$ \\
\hline SCUN & $24(69.7 \%)$ & $2(6.0 \%)$ & $8(24.2 \%)$ & $33(100.0 \%)$ \\
\hline
\end{tabular}

Table 6. The proportion of people's ethnic appearance

\begin{tabular}{|l|l|c|}
\hline & In ethnic costumes & Total \\
\hline IMNU & $12(100.0 \%)$ & $12(100.0 \%)$ \\
\hline BNU & $13(92.9 \%)$ & $14(100.0 \%)$ \\
\hline SCUN & $55(93.2 \%)$ & $59(100.0 \%)$ \\
\hline
\end{tabular}

Table 7. 'Dancing and singing' and performers' gender

\begin{tabular}{|c|c|c|c|c|}
\hline & \multicolumn{3}{|c|}{ Dancing and Singing } & Total \\
\hline \multirow[t]{3}{*}{ IMNU } & \multicolumn{3}{|c|}{$2(16.7 \%)$} & \multirow[t]{3}{*}{$12(100.0 \%)$} \\
\hline & Female & Male & Couple & \\
\hline & 0 & 0 & $2(16.7 \%)$ & \\
\hline \multirow[t]{3}{*}{$\mathrm{BNU}$} & \multicolumn{3}{|c|}{$10(71.4 \%)$} & \multirow[t]{3}{*}{$14(100.0 \%)$} \\
\hline & Female & Male & Couple & \\
\hline & $8(57.1 \%)$ & 0 & $2(14.3 \%)$ & \\
\hline \multirow[t]{3}{*}{$\overline{\text { SCUN }}$} & \multicolumn{3}{|c|}{$24(40.7 \%)$} & \multirow[t]{3}{*}{$59(100.0 \%)$} \\
\hline & Female & Male & Couple & \\
\hline & $6(10.2 \%)$ & $5(8.5 \%)$ & $13(22.0 \%)$ & \\
\hline
\end{tabular}

